\title{
Dendritic Cells in Barrett's Esophagus Carcinogenesis
}

\section{An Inadequate Microenvironment for Antitumor Immunity?}

\author{
Joan Somja, ${ }^{* \dagger}$ Stephanie Demoulin, ${ }^{\dagger}$ Patrick Roncarati, ${ }^{\dagger}$ Michaël Herfs, ${ }^{\dagger}$ Noella Bletard, ${ }^{*}$ Philippe Delvenne, ${ }^{* \dagger}$ and \\ Pascale Hubert ${ }^{\dagger}$
}

From the Department of Pathology, ${ }^{*}$ University Hospital of Liege, Liege; and the Interdisciplinary Cluster in Applied Genoproteomics (GIGA), ${ }^{\dagger}$ Laboratory of Experimental Pathology, University of Liege, Liege, Belgium

\begin{abstract}
CME Accreditation Statement: This activity ("ASIP 2013 AJP CME Program in Pathogenesis") has been planned and implemented in accordance with the Essential Areas and policies of the Accreditation Council for Continuing Medical Education (ACCME) through the joint sponsorship of the American Society for Clinical Pathology (ASCP) and the American Society for Investigative Pathology (ASIP). ASCP is accredited by the ACCME to provide continuing medical education for physicians.
\end{abstract}

The ASCP designates this journal-based CME activity (“ASIP 2013 AJP CME Program in Pathogenesis”) for a maximum of 48 AMA PRA Category 1 Credit(s) ${ }^{\mathrm{TM}}$. Physicians should only claim credit commensurate with the extent of their participation in the activity.

CME Disclosures: The authors of this article and the planning committee members and staff have no relevant financial relationships with commercial interests to disclose.

Accepted for publication

February 28, 2013.

Address correspondence to Pascale Hubert, Ph.D., Laboratory of Experimental Pathology, University of Liege, Pathology Tower B23, Sart-Tilman, B-4000 Liege, Belgium. E-mail: p.hubert@ulg.ac.be.

\begin{abstract}
Barrett's esophagus corresponds to the replacement of the normal esophageal squamous epithelium by a columnar epithelium through a metaplastic process. This tissue remodeling is associated with chronic gastroesophageal reflux and constitutes a premalignant lesion leading to a 30- to 60-fold increase in the risk to evolve into esophageal adenocarcinoma. The present study aimed to investigate a possible immune evasion in Barrett's esophagus favoring esophageal adenocarcinoma development. We demonstrated that myeloid and plasmacytoid dendritic cells are recruited during the esophageal metaplasia-dysplasia-carcinoma sequence, through the action of their chemoattractants, macrophage inflammatory protein $3 \alpha$ and chemerin. Next, we showed that, in contrast to plasmacytoid dendritic cells, myeloid dendritic cells, co-cultured with Barrett's esophagus and esophageal adenocarcinoma cell lines, display a tolerogenic phenotype. Accordingly, myeloid dendritic cells co-cultured with esophageal adenocarcinoma cell lines stimulated regulatory $\mathrm{T}$ cell differentiation from naïve $\mathrm{CD}^{+}{ }^{+} \mathrm{T}$ cells. In agreement with those results, we observed that both metaplastic areas and (pre)malignant lesions of the esophagus are infiltrated by regulatory T cells. In conclusion, soluble factors secreted by epithelial cells during the esophageal metaplasia-dysplasia-carcinoma sequence influence dendritic cell distribution and promote tumor progression by rendering them tolerogenic. (Am J Pathol 2013, 182: 2168-2179; http://dx.doi.org/10.1016/j.ajpath.2013.02.036)
\end{abstract}

Barrett's esophagus (BE) is defined by the replacement of the normal esophageal squamous epithelium by a metaplastic columnar epithelium containing true goblet cells on histological examination. ${ }^{1} \mathrm{BE}$ is considered as an adaptive response after chronic gastroesophageal reflux. ${ }^{2} \mathrm{BE}$ can be classified histologically into four groups [no dysplasia, indefinite for dysplasia, low-grade dysplasia (LGBE), or high-grade dysplasia (HGBE)], depending on the presence or absence of dysplastic cells in the epithelium. In the general population, BE prevalence is estimated to be between $1.6 \%$ and $6.8 \% .^{2}$ This tissue remodeling is associated with a 30 - to 60-fold increase in the risk of developing an esophageal adenocarcinoma (EAC), ${ }^{2}$ and EAC almost always arises after a metaplasia-dysplasia-carcinoma (MDC) sequence. BE remains an important health challenge. First, survival outcomes for patients with EAC remain poor despite recent

\footnotetext{
Supported by grants from the Fonds National de la Recherche Scientifique (FNRS; Brussels, Belgium) and the Fonds Léon Frédéricq, an FNRS Research Fellow grant 7.4625.09 (J.S.), and Fonds de Recherche Scientifique (FRS)-FNRS-Télévie grant 7.4512.12F (S.D.). M.H. is an FNRS postdoctoral researcher.
}

J.S. and S.D. contributed equally to this work. 
diagnostic and therapeutic improvements, with community 5 -year survival rates of $<20 \%{ }^{3,4}$ Second, the incidence of $\mathrm{BE}$ has dramatically increased in the Western world during these past years, compared with other types of cancers, with an increment of $>600 \%$. ${ }^{4,5}$

Despite improved knowledge about the interactions between immunity and cancer, regulation of the immune system during the MDC sequence is not yet fully understood. BE and EAC constitute interesting models for chronic inflammation associated with a (pre)malignant disease. ${ }^{4}$ For the most part, the development of $\mathrm{BE}$ and $\mathrm{EAC}$ is associated with a relative increase of type 2 helper T cells ${ }^{6}$ and the presence of an immunosuppressive (IL-4, IL-6, and IL-10) cytokine pattern, ${ }^{7}$ compared with gastroesophageal reflux-induced esophagitis characterized by a type 1 helper T-cell immune response, which is more appropriate for antitumor immunity.

Dendritic cells (DCs) are specialized antigen-presenting cells that provide a critical link between innate and adaptive immune responses. Human DCs are divided into two major intrinsically different subsets: myeloid DCs (mDCs), also called conventional DCs, and plasmacytoid DCs (pDCs), which differ from $\mathrm{mDCs}$ in their transcriptional program, phenotypic markers, and immunological functions. ${ }^{8} \mathrm{mDCs}$ play a crucial role in the regulation of adaptive immunity by their unique ability to induce a primary immune response in resting naïve T cells. ${ }^{8,9} \mathrm{mDCs}$, characterized by the expression of the CD1a marker, ${ }^{10,11}$ arise from bone marrow-derived myeloid progenitors and circulate in the peripheral bloodstream as precursors that home to tissues where they reside as immature cells with high endocytic activity and low T-cell activation potential. ${ }^{12}$ These $\mathrm{mDC}$ express CCR6 and are attracted via this chemokine receptor by macrophage inflammatory protein (MIP) $3 \alpha^{13}$ in tissues. On exposure to danger signals [eg, lipopolysaccharide (LPS)], immature mDCs undergo maturation characterized by an up-regulation of costimulatory and antigen-presenting molecules. ${ }^{9,14-17}$ De novo CCR7 expression allows these mature cells to migrate to local lymph nodes, where they can trigger an effective T-cell response. ${ }^{17}$ Fully mature $\mathrm{mDCs}$ are characterized by the production of the IL-12 proinflammatory cytokine, which is required for the induction of an efficient T-cell response. ${ }^{18}$ pDCs, the second subset of DCs, represent a rare population of human blood cells characterized by a rapid and massive secretion of type I interferon on activation via a Toll-like receptor-dependent recognition of pathogenic agents or danger signals. Immature pDCs present plasma cell-like morphological characteristics and selectively express CD4, CD45RA, CD123, BDCA-2, and BDCA-4, but are CD11c negative. ${ }^{19}$ Under steady-state conditions, pDCs reside in secondary lymphoid tissues, from where they are mobilized to inflammatory sites ${ }^{20}$ under pathological conditions, notably through the action of one of their chemoattractants, chemerin. ${ }^{21}$ Through their capacity to conjugate innate and adaptive immunity and to secrete soluble factors controlling cancer development, these cells are crucial actors in antitumor immunity. $^{22}$
$\mathrm{mDC}$ and $\mathrm{pDC}$ involvement in tumor immunity was shown to have a clinical impact because their infiltration in some primary tumor types has been associated with significant changes in patient survival and recurrent disease. ${ }^{9,23-29}$ It has been postulated that tumors may evade the immune system by an impairment of DC number and functions mediated by a local production of immunosuppressive cytokines, such as prostaglandin $\mathrm{E}_{2}\left(\mathrm{PGE}_{2}\right)$, receptor activator of NF- $\kappa \mathrm{B}$ ligand (RANKL), and IL-10, or by a modulation of chemokine expression. ${ }^{30}$ Moreover, accumulating evidence suggests that $\mathrm{mDCs}$ and $\mathrm{pDCs}$ recruited to the tumor microenvironment often display tolerogenic properties by promoting regulatory $\mathrm{T}$ cell (Treg) expansion or proliferation. ${ }^{31-33}$

In this study, we tested the hypothesis that impaired antitumor immunity in BE could promote the development and progression of EAC. First, we evaluated the differential density of mDCs, pDCs, and Treg cells in the MDC sequence associated with BE. Then, we evaluated the expression of chemokines (MIP3 $\alpha$ and chemerin) that could explain these changes of immune cell density in the MDC sequence. Finally, we performed in vitro studies to determine whether DC functionality is altered in the presence of soluble factors secreted by BE, HGBE, and EAC cell lines.

$A$ better understanding of the factors involved in the transformation of BE into EAC through a deregulation of antitumor immunity could allow the development of new immunotherapeutic strategies leading to effective antitumoral responses.

\section{Materials and Methods}

\section{Tissue Specimens}

A total of 100 formalin-fixed, paraffin-embedded endoscopic biopsy or surgical specimens were obtained from the Tumor Bank of the University Hospital of Liege (Liege, Belgium). Samples were reviewed by two gastrointestinal pathologists (N.B. and J.S.) and included normal esophageal mucosa $(n=20)$, BE without dysplasia $(n=$ $20)$, LGBE $(n=20)$, HGBE $(n=20)$, and $\operatorname{EAC}(n=20)$. Only EACs arising in the esophagus in the presence of adjacent Barrett's metaplasia were considered. Each individual case was classified in accordance with the Vienna classification. We also analyzed the progression potential of these cases to more severe lesions in follow-up biopsy or surgical specimens. The protocol was approved by the Ethics Committee of the University Hospital of Liege, and all human subjects provided appropriate informed consent. Clinical and pathological data were available for each patient and are summarized in Table 1.

\section{mDCs, pDCs, and Treg Cell Detection by IHC}

Paraffin-embedded sections of esophageal biopsy specimens ( $4 \mu \mathrm{m}$ thick) underwent immunostaining using an automated 
Table 1 Patients' Clinical and Pathological Features

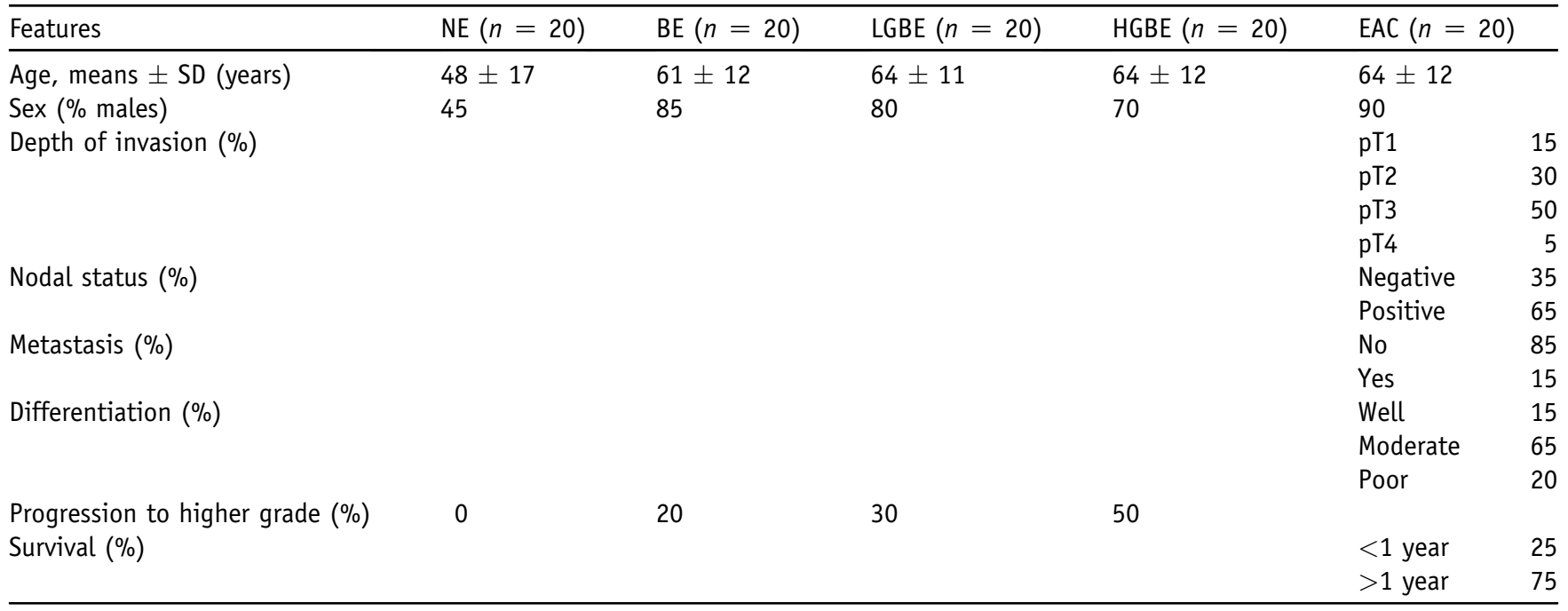

pT, pathological tumor stage (7th American Joint Committee on Cancer).

immunostainer (Ventana Medical Systems, Tucson, AZ) with antibodies directed against human CD1a (Novocastra, Newcastle, UK), BDCA-2 (Dendritics, Lyon, France), or forkhead box P3 (FoxP3; eBioscience, San Diego, CA) (Table 2). An amplification kit (Ventana Medical Systems) and a detection system including diaminobenzidine (Dako, Glostrup, Denmark) as chromogen were used during the automated procedure. Archival lymph node sections were used as positive controls. For negative controls, the primary antibody was omitted. The mean number of mDCs, pDCs, and Treg cells in each patient was calculated by counting these cells (original magnification, $\times 400$ ) in the 10 most cellular microscopic fields, also called hot spots. Inflammatory cells were quantified separately in the epithelium and lamina propria for CD1a-positive cells. Treg cells and pDCs were essentially limited to the lamina propria in the entire MDC sequence.

Double immunostaining with FoxP3 and CD1a was performed to analyze a possible colocalization of Treg cells with $\mathrm{CD} \mathrm{a}^{+}$mDCs. Briefly, after FoxP3 ${ }^{+}$cell staining, sections were washed and antigens were retrieved with heating in a pressure cooker. Then, slides were incubated with anti-CD1a antibody for 1 hour. After rinsing, the sections were incubated with the secondary antibody, and antigen visualization was performed by using the EnVision G/2 system, Permanent Red (Dako).

Table 2 Antibodies Used for IHC and Flow Cytometry Analysis

\begin{tabular}{lclll}
\hline Antibody & Dilution & Clone & Species & Company name \\
\hline CD1a & Prediluted & MTB1 & Mouse & Novocastra \\
FoxP3 & $1: 50$ & $236 A / E 7$ & Mouse & eBioscience \\
BDCA2 & $1: 50$ & $124 B 3.13$ & Mouse & Dendritics \\
MIP3 $\alpha /$ CCL20 & $1: 100$ & NA & Rabbit & Abcam (Cambridge, MA) \\
Chemerin & $1: 1000$ & NA & Rabbit & Phoenix Pharmaceuticals (Burlingame, CA) \\
RANKL & $1: 20$ & 70525 & Mouse & R\&D Systems (Minneapolis, MN) \\
CD1a-FITC & $1: 20$ & NA1/34 & Mouse & Dako (Glostrup, Denmark) \\
CD14-PE & $1: 20$ & TÜK & Mouse & Dako \\
CD80-PE & $1: 10$ & $2 D 10.4$ & Mouse & eBioscience \\
CD83-PE & $1: 20$ & HB15e & Mouse & BD Pharmingen (Franklin Lakes, NJ) \\
CD86-PE & $1: 20$ & C2331 (FUN-1) & Mouse & BD Pharmingen \\
HLA-DR-PE & $1: 20$ & AB3 & Mouse & Dako \\
HLA-ABC-PE & $1: 20$ & W6/32 & Mouse & eBioscience \\
CCR7-PE & $1: 20$ & 150503 & Mouse & R\&D Systems \\
CD123-FITC & $1: 20$ & AC145 & Mouse & Miltenyi Biotec, GmBH (Bergisch Gladbach, Germany) \\
CD11c-APC & $1: 20$ & B-ly6 & Mouse & BD Pharmingen \\
BDCA-4-PE & $1: 20$ & AD5-17F6 & Mouse & Miltenyi Biotec, GmBH \\
CD40-PE & $1: 20$ & $5 C 3$ & Mouse & BD Pharmingen \\
\hline
\end{tabular}

APC, antigen-presenting cell; NA, not available. 
MIP3 $\alpha$, Chemerin, and RANKL Detection by IHC

Paraffin-embedded sections ( $4 \mu \mathrm{m}$ thick) were deparaffinized in xylene and rehydrated through a graded ethanol series, and antigen was retrieved with EDTA solution combined with heating in a pressure cooker for MIP3 $\alpha$ and citrate buffer, combined with heating in a microwave oven for RANKL. Antigen retrieval was unnecessary for chemerin. Slides were peroxidase blocked with peroxidaseblocking solution (Dako) for 10 minutes and then were incubated with the primary antibody anti-MIP3 $\alpha$ (Abcam, Cambridge, MA) or anti-RANKL (R\&D Systems, Minneapolis, MN) (Table 2) for 1 hour and detected with the EnVision system (Dako) for 30 minutes. Other slides were incubated with primary anti-chemerin antibody (Phoenix Pharmaceuticals, Burlingame, CA) (Table 2) for 2 hours and detected with the LSAB2 System-horseradish peroxidase kit (Dako). Colorimetric detection was completed with diaminobenzidine (Dako) for 5 minutes. Slides were then counterstained with hematoxylin. MIP3 $\alpha$, chemerin, and RANKL expression in the epithelium was evaluated, as previously described, ${ }^{34}$ by a semiquantitative score of the intensity and extent of the staining according to an arbitrary scale.

\section{$\mathrm{mDC}$ and $\mathrm{pDC}$ Generation}

mDCs were generated from $\mathrm{CD} 34^{+}$hematopoietic progenitor cells, as previously described. ${ }^{35}$ Briefly, CD $34^{+}$cells were isolated from cord blood and cultured for 7 days with $20 \mathrm{ng} / \mathrm{mL}$ human stem cell factor (Peprotech, Rocky Hill, $\mathrm{NJ}), 10 \mathrm{ng} / \mathrm{mL}$ thrombopoietin (Peprotech), $25 \mathrm{ng} / \mathrm{mL} \mathrm{fms}-$ like thyrosine kinase 3 ligand (Flt3L) (Peprotech), $200 \mathrm{U} / \mathrm{mL}$ granulocyte-macrophage colony-stimulating factor (Amoytop Biotech, Xiamen, China), and $100 \mathrm{U} / \mathrm{mL}$ IL-4 (ImmunoTools, Friesoythe, Germany). Every 2 to 3 days, cultures were supplemented with $200 \mathrm{U} / \mathrm{mL}$ granulocyte-macrophage colony-stimulating factor and $100 \mathrm{U} / \mathrm{mL}$ IL-4. As previously described, ${ }^{36}$ pDCs were generated from cord blood CD $34^{+}$ hematopoietic progenitor cells cultured for 21 days in the presence of $10 \mathrm{ng} / \mathrm{mL}$ TPO, $100 \mathrm{ng} / \mathrm{mL}$ Flt $3 \mathrm{~L}$, and $20 \mathrm{ng} / \mathrm{mL}$ IL-3 (Peprotech). All human samples were collected according to a protocol approved by the Ethics Committee of the University Hospital of Liège.

\section{Co-Cultures of mDCs or pDCs in the Presence of Esophageal Cell Lines}

Human SV40-immortalized normal esophageal (NE) squamous epithelial cell line (HET1A) was obtained from ATCC (Manassas, VA). Barrett's esophageal hTERT-immortalized cell lines CPA (nondysplastic metaplasia) and CPD (highgrade dysplasia) were kind gifts from Prof. Peter Rabinovitch (University of Washington, Seattle). The human esophageal adenocarcinoma cell line, JH Eso Ad1, was kindly provided by Prof. James Eshleman (Johns Hopkins
University, Baltimore, MD). Human esophageal adenocarcinoma cell line, OE33, was purchased from the European Collection of Cell Cultures (Salisbury, UK). Cell cultures were maintained following European Collection of Cell Cultures and ATCC reported methods. Co-cultures were initiated by seeding HET1-A, CPA, CPD, OE33, and JHEso Ad1 cell lines $\left(2.5 \times 10^{4}\right.$ cells $\left./ \mathrm{mL}\right)$ or medium alone on $0.4-\mu \mathrm{m}$ pore size membrane inserts (Nunc, Roskilde, Denmark) in 6-well plates, into which $\mathrm{mDCs}$ or pDCs generated as previously described, were seeded at $0.5 \times 10^{5}$ and $0.5 \times 10^{6}$ cells $/ \mathrm{mL}$, respectively. For experiments using $\mathrm{mDCs}$, inserts were extracted after 6 days of co-culture, and $1 \mu \mathrm{g} / \mathrm{mL}$ LPS (Sigma-Aldrich, St. Louis, MO) was added to the wells for 24 hours to induce mDC maturation. For experiments using pDCs, inserts were removed after 24 hours of co-culture, and $12 \mu \mathrm{g} / \mathrm{mL}$ of $\mathrm{CpG}$ oligodeoxynucleotide (ODN) 2216 [5'-ggGGGACGATCGTCgggggg-3' (lowercase letters represent phosphorotioate linkage); Eurogentec, Seraing, Belgium] was added to the wells to induce pDC maturation.

\section{OPG Treatment}

$\mathrm{mDC}$ co-cultures were either untreated or treated with 0.5 $\mu \mathrm{g} / \mathrm{mL}$ human recombinant osteoprotegerin (OPG; Abcam), an inhibitor of RANKL on days 1 and 3 of the co-culture. $\mathrm{mDCs}$ cultured alone or in the presence of OPG were used as controls.

\section{Flow Cytometry Analysis}

Flow cytometry studies were performed by using procedures published previously. ${ }^{36,37}$ For $\mathrm{mDC}$ studies, the following antibodies were used: $\mathrm{CD} 1 \mathrm{a}-$ fluorescein isothiocyanate, CD14-phosphatidylethanolamine (PE), CD80PE, CD83-PE, CD86-PE, HLA-DR-PE, HLA-ABC-PE, and CCR7-PE (Table 2). For pDC studies, the following antibodies were used: CD123-fluorescein isothiocyanate, CD11c-antigen-presenting cell, BDCA-4-PE, CD40-PE, CD83-PE, CD86-PE, CCR7-PE, and HLA-DR-PE (Table 2). Fluorescence intensity and positive cell percentages were measured on an FACSCanto II flow cytometer (Becton Dickinson, Franklin Lakes, NJ), and data were analyzed using FACSDiva software, version 6.1.2 (Becton Dickinson).

\section{ELISA for IL-10, IL-12p70, and RANKL}

Supernatants collected from co-culture experiments using mDCs were assessed for IL-10, IL-12p70, and RANKL concentrations by using ELISA kits, according to the manufacturer's instructions [IL-10 (Invitrogen, Carlsbad, CA), IL-12p70 (R\&D Systems), and RANKL (Biomedica, Vienna, Austria)]. All assays were performed using duplicate samples. 


\section{Treg Cell Induction Assay}

The assay was performed by culturing $\mathrm{mDCs}$ (stimulator cells) isolated from co-culture experiments with allogeneic $\mathrm{CD} 4^{+} \mathrm{T}$ cells (responder cells) sorted from peripheral blood mononuclear cells using the MACS CD4 ${ }^{+} \mathrm{T}$ Cell Isolation Kit (Miltenyi Biotec GmBH, Bergisch Gladbach, Germany), according to the manufacturer's protocol. The stimulator-toresponder ratio corresponded to 1:10, and cells were placed in RPMI 5\% human pooled AB serum (Invitrogen) in 6-well plates (Nunc) for 6 days. mDCs cultured alone were used as controls.

\section{Quantitative FoxP3 Real-Time PCR}

Total RNA $(1 \mu \mathrm{g})$ extracted from Treg cell induction assays (RNeasy minikit; Qiagen, Valencia, CA) was reverse transcribed using Superscript II reverse transcriptase (Invitrogen), according to manufacturer's instructions. Quantitative realtime PCR was then performed using Power SYBR Green
Master Mix (Eurogentec) and the following primer sequences: FOXP3, 5'-CAGCACATTCCCAGAGTTCCTC-3' (forward) and $5^{\prime}$-GCGTGTGAACCAGTGGTAGATC-3' (reverse); and glyceraldehyde-3-phosphate dehydrogenase, 5'-ACCAGGTGGTCTCCTCTGAC- $3^{\prime}$ (forward) and 5'-TGCTGTAGCCAAATTCGTTG-3' (reverse) (Eurogentec). All of the experiments were performed in duplicate using the ABIPrism 7700 Sequence Detection System (Applied Biosystems, Foster City, CA), and negative controls (master mix without any cDNA) were added in each run. The results were analyzed by comparative $C_{T}$ values and reference gene $C_{T}$ values and normalized by glyceraldehyde-3-phosphate dehydrogenase as an internal control.

\section{Statistical Analysis}

Statistical analyses were performed by using GraphPad Prism software, version 4.00 (GraphPad Software, San Diego, CA). The data were not normally distributed. Nonparametric tests, such as the Kruskal-Wallis and $U$-test were then used, and
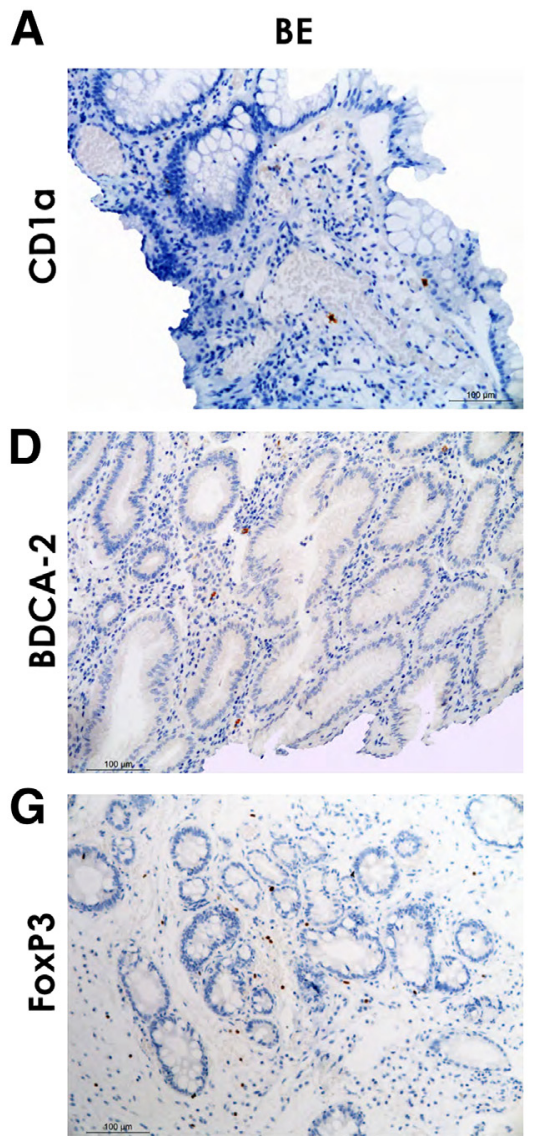

B

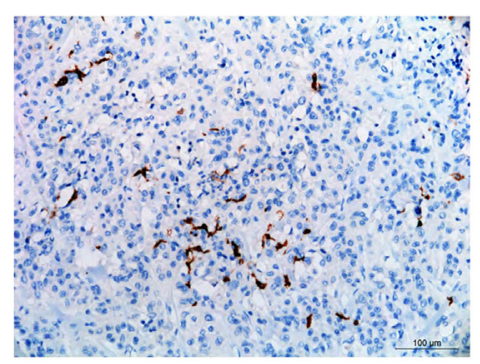

E

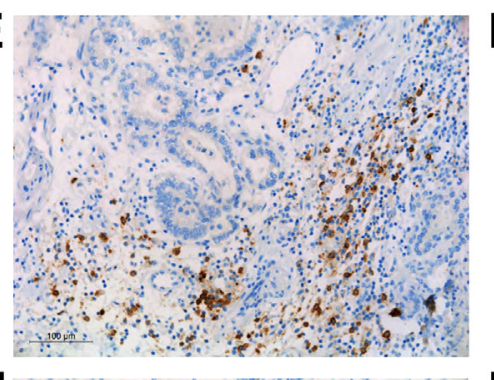

$\mathbf{H}$

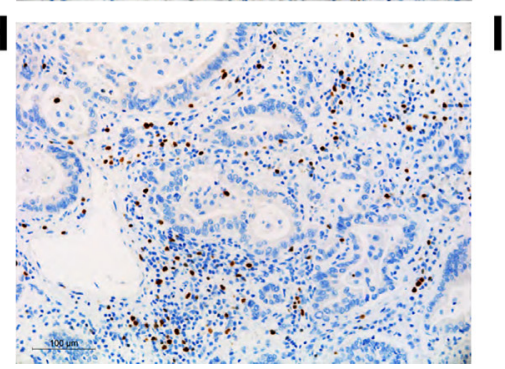

C
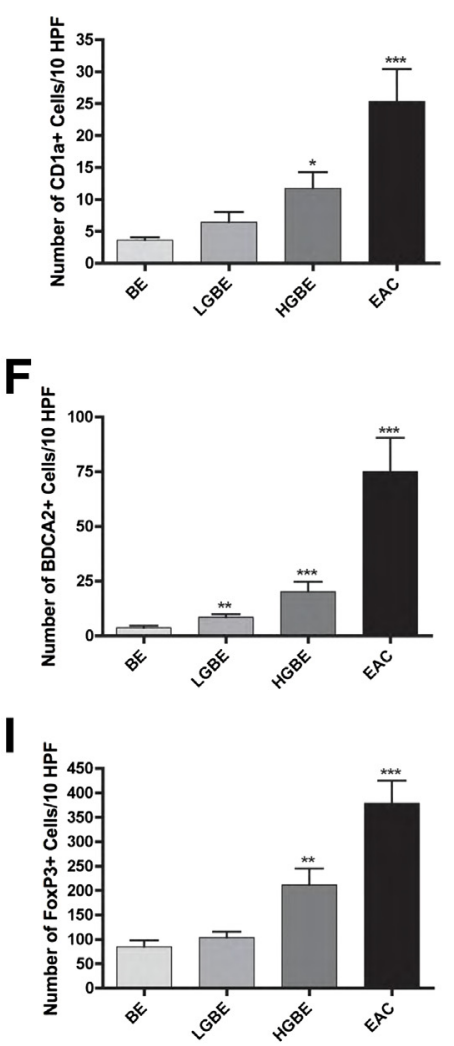

Figure $1 \mathrm{mDC}, \mathrm{pDC}$, and Treg densities increase along the MDC sequence. CD1a, BDCA-2, and FoxP3 immunostaining in BE and EAC specimens. A and B: BE displays a low density of $C D 1 a^{+}$cells in the lamina propria compared with $E A C$, which is associated with a relative increased density of DCs. $D$ and $\mathbf{G}$ : $B E$ shows few BDCA-2 $2^{+}$and Fox $3^{+}$cells. These cells are almost exclusively localized in the lamina propria. D, E, G, and $\mathbf{H}: \mathrm{BDCA}-2^{+}$and FoxP3 ${ }^{+}$cell numbers are higher in EAC compared with BE. C, F, and I: Evaluation by IHC of the number of CD1a ${ }^{+}, \mathrm{BDCA}-2^{+}$, and FoxP3 ${ }^{+}$cells per 10 high-power fields (HPFs) in BE, LGBE, HGBE, and EAC specimens. C: We observed modifications of $\mathrm{CD} 1 \mathrm{a}^{+}$cell densities within the sequence MDC. The development of EAC was associated with an increased density of mDCs compared with BE. F and I: BDCA-2 ${ }^{+}$and FoxP3 $3^{+}$cell numbers increased during the MDC sequence. Original magnification, $\times 200(\mathbf{A}, \mathbf{B}, \mathbf{D}, \mathbf{E}, \mathbf{G}$, and $\mathbf{H})$. ${ }^{\star} P<0.05,{ }^{* *} P<0.01$, and ${ }^{* * *} P<0.001$ compared with BE. Statistical significance was calculated using a $U$-test. 
differences were considered as statistically significant when $P<0.05$.

\section{Results}

$\mathrm{mDC}, \mathrm{pDC}$, and Treg Density Is Increased Along the MDC Sequence

To evaluate the immune cell infiltration, focusing on mDCs, pDCs, and Treg cells in BE carcinogenesis, the density of CD1a-, BDCA-2-, and FoxP3-positive cells was evaluated by immunohistochemistry (IHC). Examples of representative IHC staining are presented in Figure 1. BE displayed a low density of $\mathrm{CD} 1 \mathrm{a}^{+}$cells in the lamina propria with an irregular distribution between the glands (Figure 1A). EAC was associated with a relatively increased density of $\mathrm{CD} 1 \mathrm{a}^{+}$cells compared with BE $(P<0.001)$ (Figure 1B). Semiquantitative analysis showed modifications of $\mathrm{CD} 1 \mathrm{a}^{+} \mathrm{mDC}$ density within the MDC sequence (Figure 1C). HGBE was associated with a significant increase in the density of $\mathrm{CD}^{+} \mathrm{a}^{+} \mathrm{mDCs}$ compared with BE $(P<0.05)$. The development of EAC was also associated with a relatively increased density of $\mathrm{CD}_{1} \mathrm{a}^{+}$mDCs compared with $\operatorname{LGBE}(P<0.001)$ and HGBE $(P<0.05)$. BDCA- $2^{+}$pDCs showed a significant increase during the MDC sequence compared with $\mathrm{BE}$ $(P<0.01)$ (Figure $1, \mathrm{D}-\mathrm{F})$. FoxP3 ${ }^{+}$Treg cell number also increased during the MDC sequence and was significantly different from BE, $\operatorname{HGBE}(P<0.01)$, and EAC $(P<0.001)$ (Figure $1, \mathrm{G}-\mathrm{I})$.

\section{Increased Expression of MIP $3 \alpha$ and Chemerin in the MDC Sequence}

By using IHC, BE, LGBE, HGBE, and EAC specimens were evaluated for MIP $3 \alpha$ and chemerin expression. BE was often associated with weak MIP $3 \alpha$ immunoreactivity in the epithelium (Figure 2A). In LGBE (Figure 2C), MIP3 $\alpha$ expression increased significantly compared with BE $(P<0.05)$. The MIP3 $\alpha$ score was statistically higher in HGBE (Figure 2E) $(P<0.01)$ and EAC (Figure 2G) $(P<0.001)$ than in BE. Semiquantitative evaluation of MIP3 $\alpha$ intraepithelial expression is shown in Figure 2I. In the same way, chemerin was detected in the cytoplasm and nucleus of epithelial cells, often associated with diffuse stromal expression. Chemerin immunoreactivity was weak and sporadic in BE (Figure 2J). Intense immunostaining for chemerin was observed in epithelial EAC samples (Figure $2 \mathrm{H}$ ), with a significant increase compared with $\mathrm{BE}$ (Figure 2B) $(P<0.001)$. However, chemerin expression in $\mathrm{BE}$ and HGBE (Figure 2F) showed a significant decrease compared with NE $(P<0.01)$ (data not shown). We also observed a significant increase of chemerin expression from BE to LGBE $(P<0.01)$, BE to HGBE $(P<0.01)$, and HGBE to EAC $(P<0.05)$.
$\mathrm{mDCs}$ Present a Tolerogenic Phenotype in the Presence of $B E, H G B E$, and EAC Cell Lines

To evaluate the effects of the soluble factors released by epithelial cells on $\mathrm{mDCs}$ in $\mathrm{BE}$ carcinogenesis, $\mathrm{mDCs}$ were co-cultured in the presence of NE, BE, HGBE, and EAC cell lines, with transwell membranes avoiding cell-to-cell contact. After 6 days, mDCs were matured with LPS. BE, HGBE, and EAC cell lines inhibited $\mathrm{mDC}$ maturation. Indeed, mDCs generated in the presence of CPA (BE cell line) showed a lower expression of CD80, CD83, and CD86, as did other molecules involved in antigen presentation (HLA-ABC and HLA-DR) compared with control mDCs (Figure 3, A-F). A similar reduced expression of CD80 was observed when mDCs were cultured in the

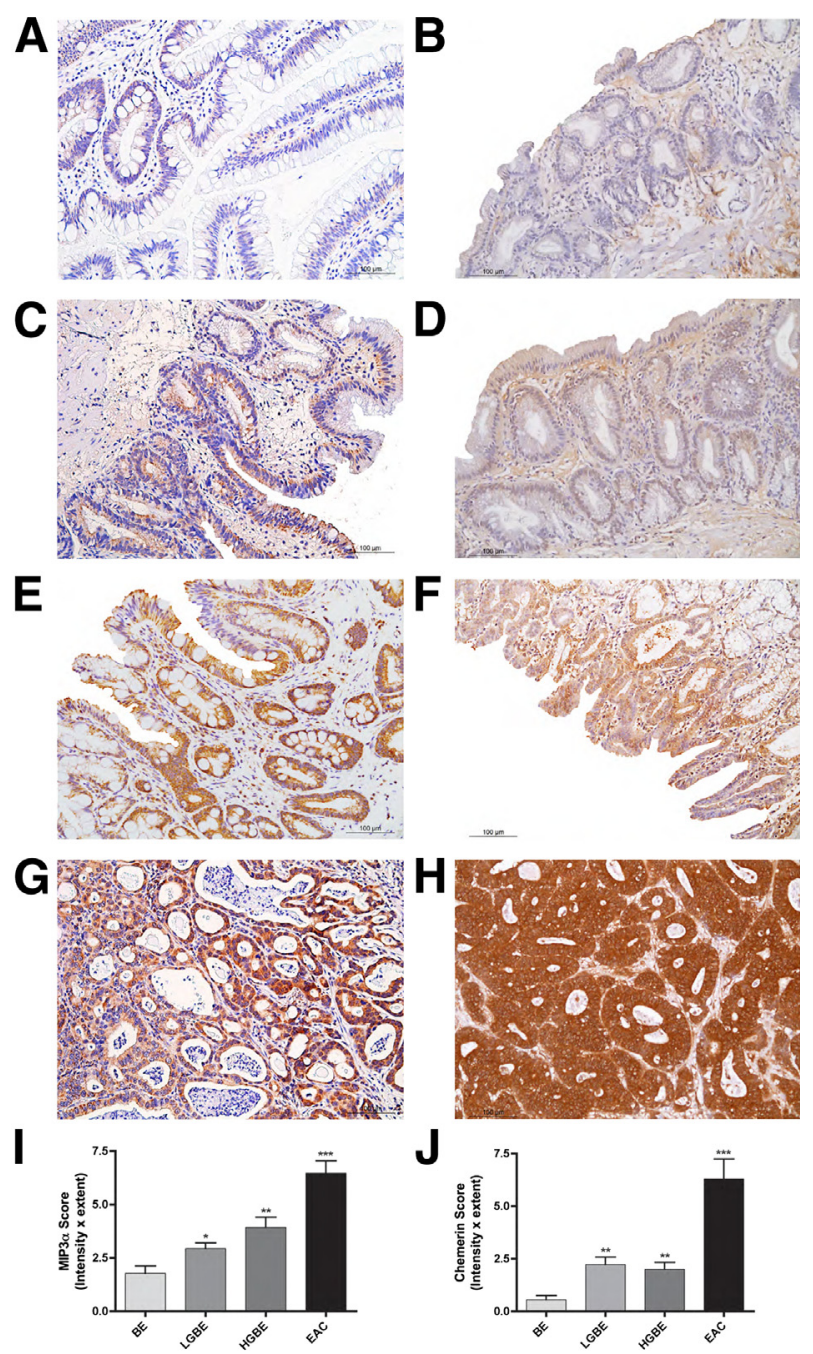

Figure 2 MIP $3 \alpha$ and chemerin expression is increased in the MDC sequence. Representative IHC examples of MIP $3 \alpha$ and chemerin expression in the epithelium of BE (A and B), LGBE (C and D), HGBE (E and $\mathbf{F}$ ), and EAC ( $\mathbf{G}$ and $\mathbf{H}$ ). I and J: Semiquantitative analysis of MIP $3 \alpha$ and chemerin expression shows a significant increased expression in $\mathrm{LGBE}, \mathrm{HGBE}$, and $\mathrm{EAC}$ compared with BE. ${ }^{*} P<0.05,{ }^{*} P<0.01$, and ${ }^{* * *} P<0.001$ compared with NE. Statistical significance was calculated by using a $U$-test. Original magnification, $\times 200(\mathbf{A}-\mathbf{H})$. 


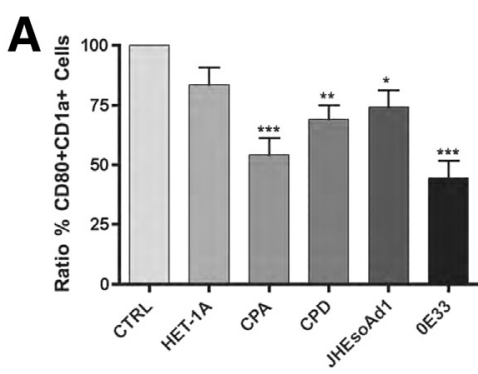

D

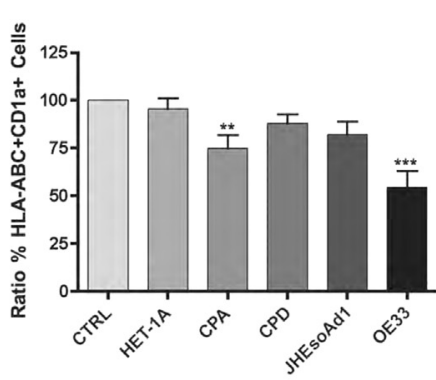

G

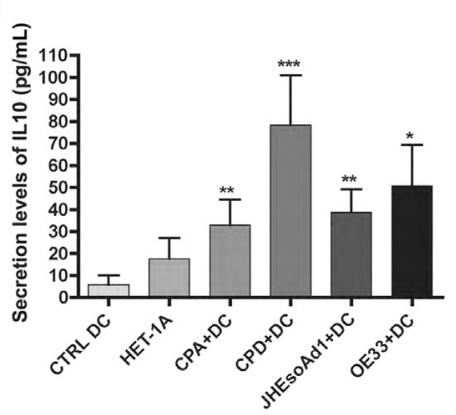

B

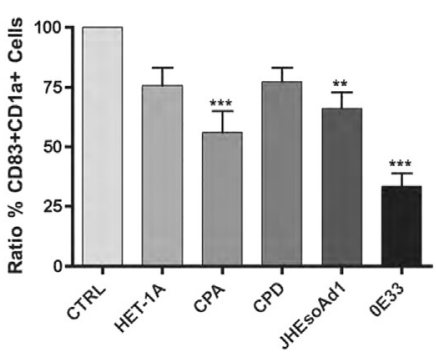

E

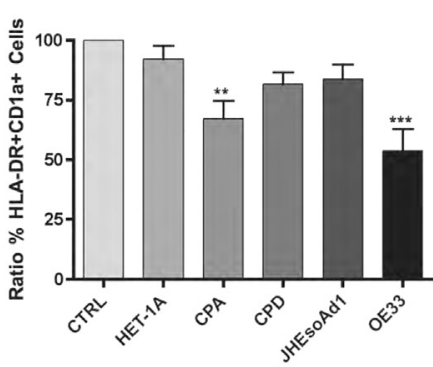

H

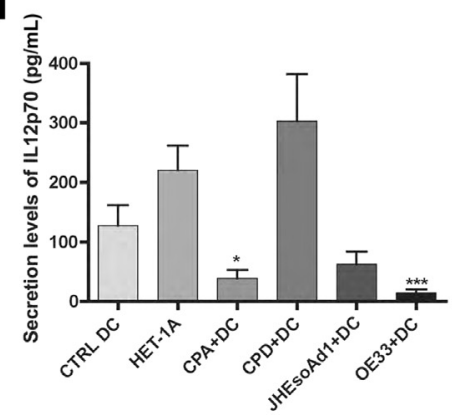

C

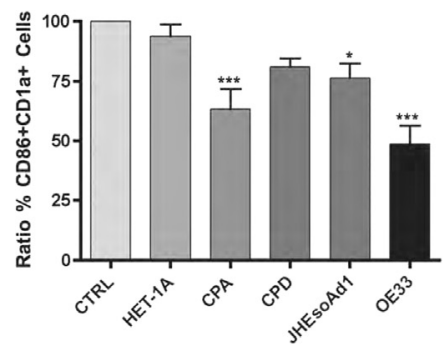

F

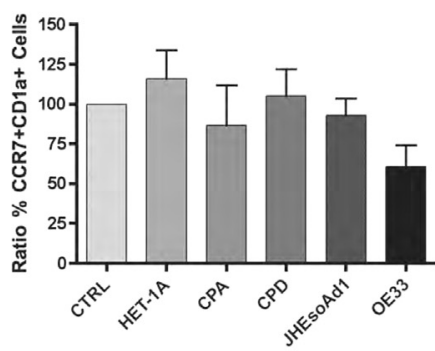

Figure $3 \mathrm{mDCs}$ display an immature $\mathrm{IL}-10^{\mathrm{High}} \mathrm{IL}-12^{\mathrm{Low}}$ tolerogenic phenotype in the presence of $\mathrm{BE}$ and $\mathrm{EAC}$ cell lines. A-F: Analysis of mDC phenotype after co-culture with normal esophageal squamous cells (HET-1a), Barrett's esophagus (CPA), high-grade Barrett's esophagus (CPD), and esophageal adenocarcinoma (0E33 and JHEsoAd1) cell lines. After 6 days of co-culture and 24 hours of incubation with LPS, analysis of the cell surface expression of CD80, CD83, CD86, HLA-DR, HLA-ABC, and CCR7 was performed using flow cytometry. Mean percentages of positive cells and SDs obtained in 12 different experiments are reported. ${ }^{*} P<0.05,{ }^{*} P<0.01$, and ${ }^{* *} P<0.001$ compared with control mDCs (CTRL). Statistical significance was calculated by using a Kruskal-Wallis test. $\mathbf{G}$ and $\mathbf{H}$ : Secreted cytokine levels (IL-10 and IL-12p70) in culture supernatants of mDCs co-cultured with normal esophageal squamous cells (HET-1a), Barrett's esophagus (CPA), high-grade Barrett's esophagus (CPD), and esophageal adenocarcinoma (0E33 and JHEsoAd1) cell lines. The secretion levels were measured by ELISA after 6 days of co-culture and 24 hours of incubation with LPS. mDCs cultured alone were used as controls (CTRL DC). Data are presented as means and SDs of 10 independent experiments performed in duplicate. ${ }^{*} P<0.05,{ }^{*} P<0.01$, and ${ }^{* * *} P<0.001$ compared with controls. Statistical significance was calculated by using a $U$-test.

presence of CPD (HGBE cell lines). In addition, OE33 and JhEsoAd1 (EAC cell lines) were also associated with a reduced expression of CD80, CD83, and CD86 in cocultured mDCs. In contrast, no significant difference was observed when HET-1a (normal esophageal squamous cell line) was used. Consistent with their reduced immunostimulatory capacity, mDCs generated in the presence of $\mathrm{BE}$ and EAC cell lines produced higher levels of IL-10 and lower amounts of IL-12 compared with control mDCs (Figure 3, G and H). HET-1a cells did not alter the secretion of these two cytokines. The fact that BE and EAC cell lines inhibit dendritic cell maturation and IL-12p70 secretion, while enhancing IL-10 secretion in response to LPS, suggests a tolerogenic mDC phenotype. On the contrary, pDC maturation status was not significantly modified after they were co-cultured with NE, BE, HGBE, and EAC cell lines, compared with pDCs cultured alone (data not shown).

mDCs Co-Cultured with BE, HGBE, and EAC Stimulate Treg Cell Differentiation from Naïve $\mathrm{CD}^{+}{ }^{+} \mathrm{T}$ Cells

By using a Treg cell induction assay, we showed that mDCs co-cultured with BE, HGBE, and EAC cell lines stimulate the differentiation of naïve $\mathrm{CD} 4^{+} \mathrm{T}$ cells into Treg cells.

However, only mDCs co-cultured with EAC cell lines (JH Eso Ad1 and OE33) induce a significant increase in the expression of FoxP3 mRNA $(P<0.05)$ in $\mathrm{T}$ cells when compared with FoxP3 induction in T cells exposed to mDCs cultured alone. These results confirmed that mDCs differentiated in the presence of EAC cell lines are able to induce a tolerogenic response (Figure 4A). 
A

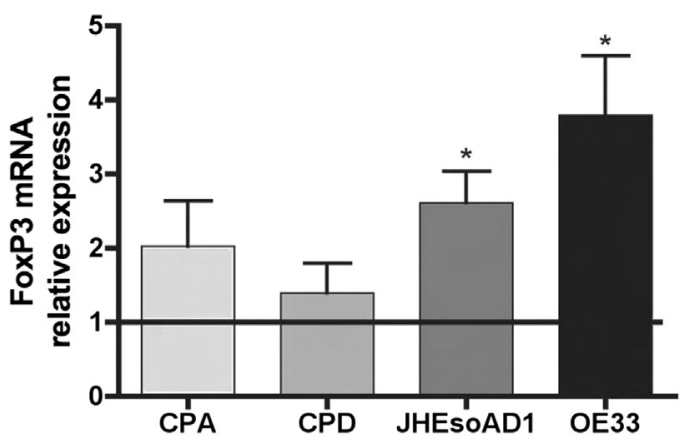

B

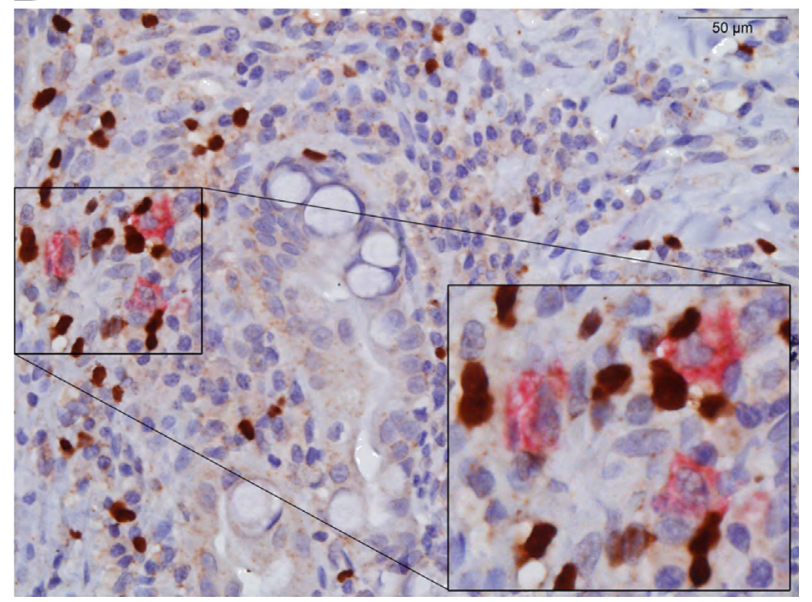

Figure $4 \mathrm{mDCs}$ co-cultured with $\mathrm{BE}, \mathrm{HGBE}$, and $\mathrm{EAC}$ induce Treg differentiation in vitro and colocalize with Treg cells in vivo in EAC. A: $\mathrm{mDC}$ s isolated from previously described co-culture experiments were seeded with allogeneic $\mathrm{CD}^{+} \mathrm{T}$ cells for 6 days. $\mathrm{mDC}$ s cultured alone were used as controls. Quantitative real-time PCR analysis was performed to assess FoxP3 expression in the samples collected. We observed that EAC cell lines significantly increase the ability of $\mathrm{mDCs}$ to stimulate Treg cell differentiation compared with $\mathrm{mDC}$ c cultured alone $(n=3)$. Statistical significance was calculated by using a $U$-test. ${ }^{*} P<0.05$. B: $\mathrm{CD} \mathrm{a}^{+}$and $\mathrm{FoxP3}^{+}$cells in an EAC surgical specimen. $\mathrm{CD} 1 \mathrm{a}^{+}$cells are stained red, whereas FoxP3 ${ }^{+}$cells are visualized in brown. A close localization between $\mathrm{CD} 1 \mathrm{a}^{+}$cells and FoxP $3^{+}$cells is observed in the peritumoral area. Original magnification, $\times 400$.

\section{$\mathrm{mDCs}$ and Treg Cells Colocalize in EAC}

Double immunostaining with CD1a and FoxP3 revealed the existence of a direct contact between $\mathrm{FoxP}^{+}$Treg cells and $\mathrm{CD} \mathrm{a}^{+}$mDCs. These cells formed several clusters within the lamina propria in the four tested specimens of EAC. An example of these $\mathrm{CD} 1 \mathrm{a}^{+} \mathrm{mDCs}$ and $\mathrm{FoxP}^{+}$Treg cell clusters is presented in Figure 4B.

\section{RANKL Expression Increases during the MDC Sequence}

RANKL expression was investigated using IHC. EAC and HGBE epithelium showed a higher and more diffuse RANKL immunoreactivity compared with $\mathrm{BE}(P<0.01$ and $P<0.001$, respectively). In LGBE, RANKL immunoreactivity was weaker and detected in fewer cells (Figure 5, A-D). ELISA analysis in BE, HGBE, and EAC culture media confirmed that RANKL is secreted by these epithelial cell lines (Figure 5E). RANKL expression was significantly higher $(P<0.01)$ in OE33 (EAC cell line) than in CPA (BE cell line), as shown in Figure 5F. However, RANKL inhibition by OPG, a RANKL antagonist, in co-cultures was not sufficient to significantly reverse the tolerogenic phenotype of mDCs (Figure 5, G-L).

\section{Discussion}

$\mathrm{BE}$ is a premalignant lesion presenting a high risk of developing an EAC. The malignant transformation of BE could result from the presence of immune alterations that would prevent the development of an efficient antitumor immune response. Metaplastic and/or inflammatory cells could generate an immunosuppressive environment and promote malignant transformation in metaplastic areas by altering antitumor immunity. ${ }^{38}$ Indeed, Moons et $\mathrm{al}^{6}$ showed that the mean proportion of $\mathrm{CD}^{+}$-effective $\mathrm{T}$ cells in $\mathrm{BE}$ is less than in NE. Moreover, higher IL-10 mRNA levels were reported in $\mathrm{BE},{ }^{39}$ suggesting a decreased immunosurveillance during the esophageal MDC sequence.

Because previous reports showed that DCs can present an altered functionality and/or tolerogenic activities in a tumor setting, ${ }^{40-43}$ we investigated whether these cells play a role in the evolution of BE to AEC. First, we demonstrated that $\mathrm{mDCs}$ and $\mathrm{pDCs}$ are present in esophageal tissues during the MDC sequence. In all BE samples, $\mathrm{CD} 1 \mathrm{a}^{+} \mathrm{mDCs}$ were found to be widely distributed around metaplastic glands. The number of $\mathrm{CD}_{1} \mathrm{a}^{+} \mathrm{mDCs}$ in $\mathrm{BE}$ was significantly less than that in NE (data not shown). In contrast, the development of EAC from LGBE was associated with a relatively increased density of mDCs. These data suggest an initial decrease of $\mathrm{mDC}$ homing in $\mathrm{BE}$ compared with $\mathrm{NE}$, followed by an increased infiltration from LGBE to EAC. The increased amount of $\mathrm{mDCs}$ along the MDC sequence could be due to a sequestration of immature $\mathrm{mDCs}$ within the tissue and/or a tumor-induced maturation stop of tumorinfiltrating mDCs. Interestingly, we also demonstrated that the number of BDCA-2 $2^{+}$pDCs was significantly increased in the MDC sequence. The changes in $\mathrm{mDC}$ and $\mathrm{pDC}$ densities may probably be explained by the high expression in the same areas of their respective chemotactic factors, MIP3 $\alpha$ and chemerin. Unexpectedly, despite the few infiltrating pDCs, IHC analyses showed a high expression of chemerin in the NE (data not shown). Even if the role of chemerin in the NE is still unknown, it can be speculated that, under homeostatic conditions, chemerin may represent a mechanism allowing a rapid attraction of effector cells on the generation of pathogenic signals, as suggested in normal skin by Albanesi et al. ${ }^{44}$ In addition, proteinases required for chemerin activation are likely to be present in BE, LGBE, HGBE, and EAC. Indeed, BE and EAC are often associated with an important inflammatory infiltrate, which likely contains chemerin-activating proteases, such as 


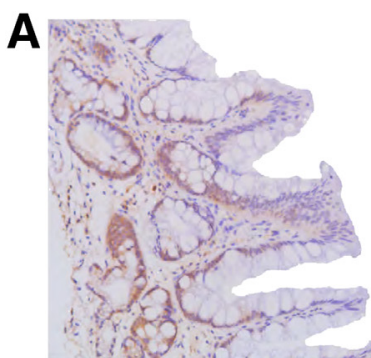

D
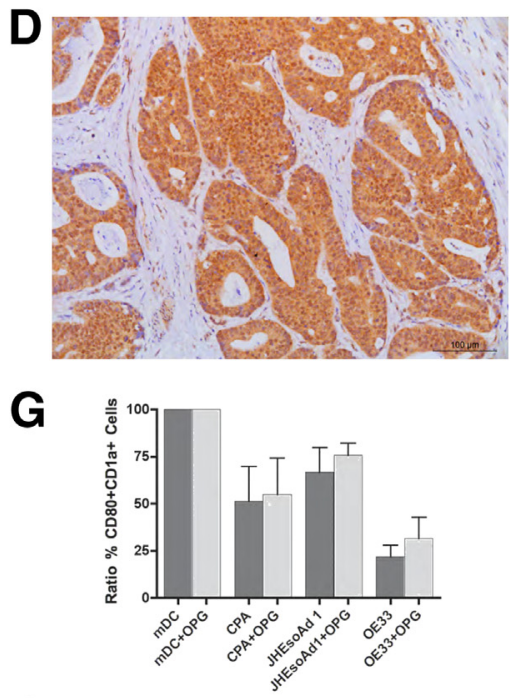

J

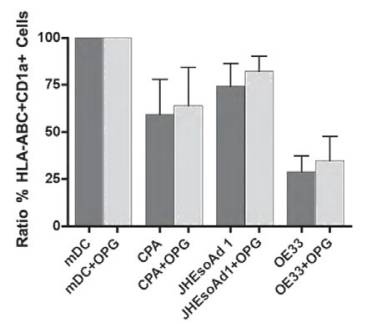

B

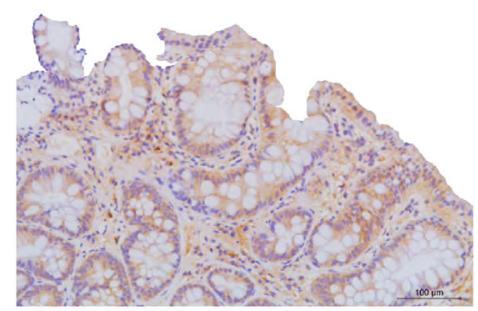

E

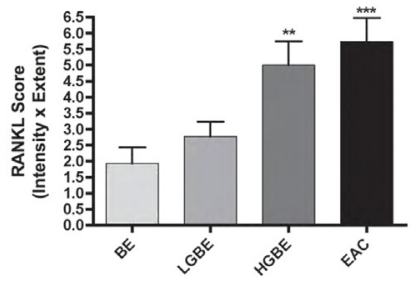

H

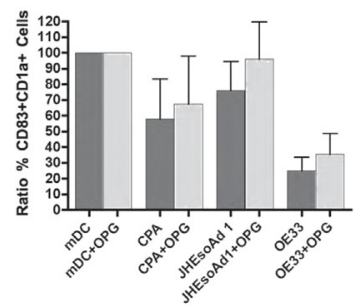

K

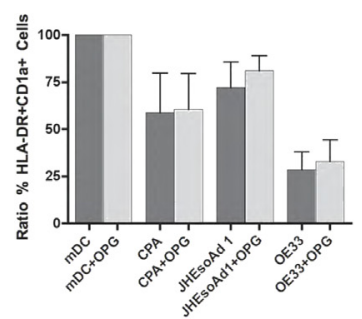

C

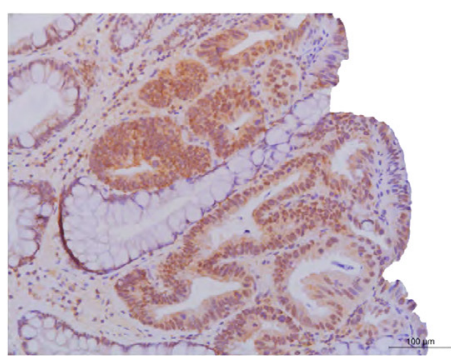

F

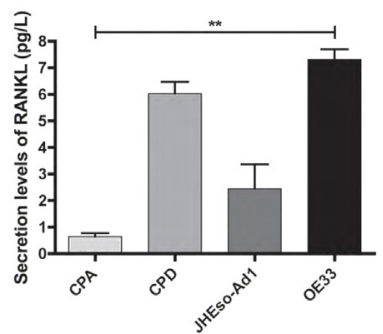

I

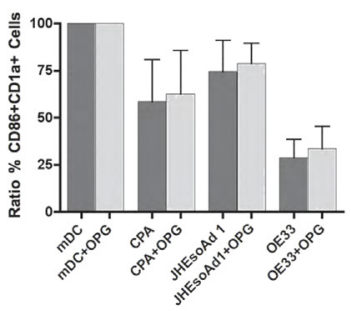

L

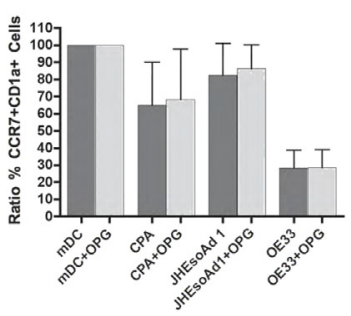

Figure 5 RANKL expression increases in the MDC sequence, but its inhibition is not sufficient to reverse the tolerogenic profile of mDCs. Representative immunostaining examples of RANKL expression in the epithelium of BE (A), low-grade Barrett's esophagus (B), high-grade Barrett's esophagus (C), and EAC (D). Original magnification, $\times 200$ (A-D). E: Semiquantitative analysis of RANKL expression showing a significant increased expression in HGBE and EAC compared with BE. ${ }^{* *} P<0.01,{ }^{* * * P}<0.001$ compared with BE. Statistical significance was calculated using a U-test. F: Secreted RANKL levels in culture supernatants of Barrett's esophagus (CPA), high-grade Barrett's esophagus (CPD), and esophageal adenocarcinoma (OE33 and JHEsoAd1) cell lines. The secretion levels were measured by ELISA. Data are presented as means and SDs of four independent experiments performed in duplicate. ${ }^{* *} P<0.01$. Statistical significance was calculated by using a U-test. G-L: Analysis of $\mathrm{mDC}$ phenotype after co-culture in the presence of Barrett's esophagus (CPA), high-grade Barrett's esophagus (CPD), and esophageal adenocarcinoma (0E33and JHEsoAd1) cell lines either untreated or treated with human recombinant OPG. After 6 days of co-culture and 24 hours of incubation with LPS, analysis of the cell surface expression of CD80, CD83, CD86, HLA-DR, HLA-ABC, and CCR7 was performed using flow cytometry. Mean percentages of positive cells and SDs obtained in four different experiments are reported herein. Statistical significance was calculated by using a $U$-test. There was no significant difference between untreated and treated cell lines.

urokinase plasminogen activator. ${ }^{45}$ Increased MIP3 $\alpha$ expression could be explained by the fact that bile acid, probably the most important toxic component of the refluxate linked to $\mathrm{BE}$, could actively induce its expression via the activation of the bile acid receptor (alias farnesoid $\mathrm{X}$ receptor). These results suggest an important role for biliary reflux in immature $\mathrm{mDC}$ homing.

The many mDCs in dysplastic BE and EAC could be intuitively associated with the induction of a functional antigen-presenting stimulation and, thus, to the development of an antitumor immune response. However, the microenvironment and the characteristics of local mDCs vary for each type of tumor. Because mDCs could have an altered maturation in the MDC sequence, a tolerogenic immune response could occur and promote immune evasion in Barrett's carcinogenesis. Production of immunosuppressive molecules may be an important mechanism by which esophageal cells from the MDC sequence could escape from immunosurveillance. Therefore, we studied the effect of soluble factors secreted by cultured human BE, HGBE, and EAC cell lines on $\mathrm{mDC}$ and $\mathrm{pDC}$ functionality. We demonstrated that these cell lines alter $\mathrm{mDC}$, but not pDC, maturation phenotype. In parallel, mDCs co-cultured with $\mathrm{BE}$ and EAC cell lines showed a tolerogenic profile of 
secreted cytokines characterized by increased IL-10 secretion, an anti-inflammatory cytokine that inhibits a type 1 helper T-cell response, ${ }^{46}$ and decreased IL-12p70 secretion, a proinflammatory cytokine required for type 1 helper T-cell responses. Indeed, mDCs with an IL-10 $0^{\text {high }}$ and IL$12^{\text {low }}$ secretion profile have been reported to promote Treg cells. $^{47,48}$

Esophageal cell lines used in this study may release different signals that could negatively affect the function of mDCs, making them functionally deficient and/or tolerogenic. Studies on several different neoplastic entities have shown that, in patients with cancer, mDCs present in the blood, tumor tissues, and/or draining lymph node are functionally defective and possess a poor T-cell stimulatory ability., ${ }^{9,-52}$ By using a Treg cell induction assay, we showed that mDCs co-cultured with BE, HGBE, and EAC stimulate Treg cell differentiation from naïve $\mathrm{CD} 4^{+} \mathrm{T}$ cells, confirming that the microenvironment notably encountered in EAC is tolerogenic. In agreement with those results, we observed that both metaplastic areas and (pre)malignant lesions of the esophagus are infiltrated by Treg cells, and a colocalization was observed between $\mathrm{mDC}$ and Treg cells in those areas. One possible explanation for this colocalization could be that their presence around (pre)malignant epithelial cells reflects an ongoing antigen-specific immune response, and localization of these clustered cells close to (pre)malignant cells could represent a tertiary lymph node tissue leading to the local generation of Treg cells. ${ }^{9}$ Thus, MIP3 $\alpha$ expression in the MDC sequence could be linked to the increased number of FoxP3 ${ }^{+}$Treg cells observed in the same areas. Interestingly, a selective recruitment of Treg cells through MIP3 $\alpha$ expression was recently described in hepatocellular carcinoma. ${ }^{53}$

Among the immunosuppressive factors potentially responsible for $\mathrm{mDC}$ alterations in the $\mathrm{MDC}$ sequence, IL- $10^{54}$ and RANKL ${ }^{55-57}$ represent interesting candidates. Indeed, IL-10-mediated inhibition of maturation has been reported to render mDCs tolerogenic. ${ }^{58}$ However, supernatants obtained from the esophageal cell lines used in this study showed an absence of IL-10 secretion (data not shown). RANK and its ligand, RANKL (alias OPG ligand), are members of the tumor necrosis factor superfamily and were first described as key regulators of bone homeostasis, mammary gland formation, and lymph node development. ${ }^{59}$ Several studies showed that the RANK-RANKL interaction has a crucial role in the regulation of the immune system. ${ }^{55-57}$ RANKL has been observed in keratinocytes of inflamed skin, and its overexpression has been linked to functional alterations of epidermal DCs and a systemic increase of Treg cells. ${ }^{55}$ Together with our data showing a significant increase of $\mathrm{FoxP}^{+}$Treg cells in the MDC sequence and the studies suggesting that epithelial RANKL controls Treg cells numbers via the activation of mDCs, ${ }^{55,60}$ the results of these experiments suggest a possible link between epithelial RANKL expression and the regulation of $\mathrm{FoxP}^{+}$Treg by mDCs in the MDC sequence. We confirmed that RANKL is expressed in the cell lines and showed, for the first time to our knowledge, a significant in vivo increase of RANKL expression in LGBE, HGBE, and EAC compared with NE. To determine whether RANKL expression in the MDC sequence is responsible for the acquisition of an altered tolerogenic phenotype by mDCs, we added OPG, a RANKL antagonist, ${ }^{61}$ to the cocultures. Because the in vitro treatment of $\mathrm{mDCs}$ with human recombinant RANKL was associated with a reduced expression of $\mathrm{mDC}$ costimulatory molecules, which was reversed after OPG addition (data not shown), we expected to reverse the alteration of the $\mathrm{mDC}$ phenotype when OPG was added to our co-cultures. However, despite a tendency to reverse the inhibitory effect of BE and EAC cell lines, OPG addition to the co-cultures did not induce a significant reversion of the $\mathrm{mDC}$ phenotype, suggesting that RANKL may not be the main mediator responsible for the $\mathrm{mDC}$ functional alteration in the MDC sequence. Because of the fact that many soluble factors are present in the tumor microenvironment, it is not surprising that the sole inhibition of RANKL was not sufficient to reverse the maturation and function of mDCs observed after their co-culture with the esophageal cell lines.

These findings suggest that additional secreted epithelial factors are involved in the induction of tolerogenic mDCs. It is also possible that the action of all secreted factors from the tumor microenvironment is required to elicit a significant effect. Other factors, such as $\mathrm{PGE}_{2}$, IL-6, ${ }^{62}$ gangliosides, ${ }^{63}$ mucin 1 (MUC1), ${ }^{64}$ transforming growth factor- $\beta$, retinoic acid, thymic stromal lymphopoietin, and cobalt protoporphyrin, ${ }^{12}$ have been shown to play a role in the inhibition of $\mathrm{mDC}$ maturation. Among these, MUC1 and $\mathrm{PGE}_{2}$, which are expressed in $\mathrm{BE}^{65}$ and EAC, ${ }^{66}$ are potential candidates. Indeed, MUC1 is highly expressed by several epithelial tumors, including breast, colon, kidney, lung, esophageal, stomach, and ovarian cancers. ${ }^{67}$ Moreover, tumor-derived MUC1 has been shown to interact with differentiating monocytes and to inhibit mDC maturation and IL-12p70 secretion, while enhancing IL-10 secretion. ${ }^{68}$ On the other hand, mDCs differentiated in the presence of $\mathrm{PGE}_{2}$ also display a tolerogenic phenotype. ${ }^{48}$ Finally, programmed death 1 and its ligand (PD-1/PD-L1) could also play a role in the immune escape observed in the Barrett MDC sequence. Accumulating data demonstrated that PD-1/PD-L1 interaction inhibits T-lymphocyte proliferation, survival, and function, induces apoptosis of tumor-specific $\mathrm{T}$ cells, and promotes the differentiation of $\mathrm{CD}^{+}{ }^{+} \mathrm{T}$-naïve cells into regulatory $\mathrm{T}$ cells in the tumor microenvironment. A high expression of PD-L1 has been described in several histological types of cancers. Interestingly, in a recent article, Loos et $\mathrm{al}^{69}$ showed an aberrant PD-L1 expression in Barrett cells. Moreover, in a multivariable analysis performed on 101 patients, these authors showed that high tumor PD-L1 expression is significantly associated with an increased risk of death from Barrett adenocarcinoma. ${ }^{69}$ 
Consequently, these results suggest that PD-L1 could represent both a potential target in the treatment of esophageal adenocarcinoma and another mechanism implicated in Barrett's carcinogenesis immune escape.

In conclusion, a better understanding of the microenvironment modifications associated with the esophageal MDC sequence and of their implication in the alterations of $\mathrm{mDC}$ functionalities may be crucial to elaborate new immunotherapies able to induce an effective antitumoral response and, indirectly, to reverse the MDC sequence.

\section{Acknowledgments}

We thank Agnès Delga (Biothèque Universitaire de Liège), the Groupe Interdisciplinaire de Génoprotéomique Appliquée (GIGA) imaging and flow cytometry platform, and Estelle Dortu for her excellent technical assistance.

\section{References}

1. Wang KK, Sampliner RE: Updated guidelines 2008 for the diagnosis, surveillance and therapy of Barrett's esophagus. Am J Gastroenterol 2008, 103:788-797

2. Gilbert EW, Luna RA, Harrison VL, Hunter JG: Barrett's esophagus: a review of the literature. J Gastrointest Surg 2011, 15:708-718

3. Jemal A, Siegel R, Ward E, Murray T, Xu J, Thun MJ: Cancer statistics, 2007. CA Cancer J Clin 2007, 57:43-66

4. Bobryshev YV, Tran D, Killingsworth MC, Buckland M, Lord RV: Dendritic cells in Barrett's esophagus and esophageal adenocarcinoma. J Gastrointest Surg 2009, 13:44-53

5. Pohl H, Welch HG: The role of overdiagnosis and reclassification in the marked increase of esophageal adenocarcinoma incidence. J Natl Cancer Inst 2005, 97:142-146

6. Moons LM, Kusters JG, Bultman E, Kuipers EJ, van Dekken H, Tra WM, Kleinjan A, Kwekkeboom J, van Vliet AH, Siersema PD: Barrett's oesophagus is characterized by a predominantly humoral inflammatory response. J Pathol 2005, 207:269-276

7. Colleypriest BJ, Ward SG, Tosh D: How does inflammation cause Barrett's metaplasia? Curr Opin Pharmacol 2009, 9:721-726

8. Belz GT, Nutt SL: Transcriptional programming of the dendritic cell network. Nat Rev Immunol 2012, 12:101-113

9. Middel P, Brauneck S, Meyer W, Radzun HJ: Chemokine-mediated distribution of dendritic cell subsets in renal cell carcinoma. BMC Cancer 2010, 10:578

10. Gregory S, Zilber M, Charron D, Gelin C: Human CD1a molecule expressed on monocytes plays an accessory role in the superantigeninduced activation of T lymphocytes. Hum Immunol 2000, 61:193-201

11. Krenacs L, Tiszalvicz L, Krenacs T, Boumsell L: Immunohistochemical detection of CD1A antigen in formalin-fixed and paraffinembedded tissue sections with monoclonal antibody 010. J Pathol 1993, 171:99-104

12. Gregori S: Dendritic cells in networks of immunological tolerance. Tissue Antigens 2011, 77:89-99

13. Greaves DR, Wang W, Dairaghi DJ, Dieu MC, Saint-Vis B, FranzBacon K, Rossi D, Caux C, McClanahan T, Gordon S, Zlotnik A, Schall TJ: CCR6, a CC chemokine receptor that interacts with macrophage inflammatory protein 3alpha and is highly expressed in human dendritic cells. J Exp Med 1997, 186:837-844

14. Caux C, Ait-Yahia S, Chemin K, de Bouteiller O, Dieu-Nosjean MC, Homey B, Massacrier C, Vanbervliet B, Zlotnik A, Vicari A: Dendritic cell biology and regulation of dendritic cell trafficking by chemokines. Springer Semin Immunopathol 2000, 22:345-369
15. Ardavin C, Martinez del Hoyo G, Martin P, Anjuere F, Arias CF, Marin AR, Ruiz S, Parrillas V, Hernandez H: Origin and differentiation of dendritic cells. Trends Immunol 2001, 22:691-700

16. Caux C, Massacrier C, Vanbervliet B, Dubois B, de Saint-Vis B, Dezutter-Dambuyant C, Jacquet C, Schmitt D, Banchereau J: CD34+ hematopoietic progenitors from human cord blood differentiate along two independent dendritic cell pathways in response to GMCSF+TNF alpha. Adv Exp Med Biol 1997, 417:21-25

17. Banchereau J, Briere F, Caux C, Davoust J, Lebecque S, Liu YJ, Pulendran B, Palucka K: Immunobiology of dendritic cells. Annu Rev Immunol 2000, 18:767-811

18. Lanzavecchia A, Sallusto F: Regulation of $\mathrm{T}$ cell immunity by dendritic cells. Cell 2001, 106:263-266

19. Dzionek A, Sohma Y, Nagafune J, Cella M, Colonna M, Facchetti F, Gunther G, Johnston I, Lanzavecchia A, Nagasaka T, Okada T, Vermi W, Winkels G, Yamamoto T, Zysk M, Yamaguchi $Y$, Schmitz J: BDCA-2, a novel plasmacytoid dendritic cell-specific type II C-type lectin, mediates antigen capture and is a potent inhibitor of interferon alpha/beta induction. J Exp Med 2001, 194:1823-1834

20. Swiecki M, Colonna M: Accumulation of plasmacytoid DC: roles in disease pathogenesis and targets for immunotherapy. Eur J Immunol 2010, 40:2094-2098

21. Bondue B, Wittamer V, Parmentier M: Chemerin and its receptors in leukocyte trafficking, inflammation and metabolism. Cytokine Growth Factor Rev 2011, 22:331-338

22. Demoulin S, Herfs M, Delvenne P, Hubert P: Tumor microenvironment converts plasmacytoid dendritic cells into immunosuppressive/tolerogenic cells: insight into the molecular mechanisms. J Leukoc Biol 2013, 93:343-352

23. Halama N, Michel S, Kloor M, Zoernig I, Pommerencke T, von Knebel Doeberitz M, Schirmacher P, Weitz J, Grabe N, Jager D: The localization and density of immune cells in primary tumors of human metastatic colorectal cancer shows an association with response to chemotherapy. Cancer Immun 2009, 9:1

24. Pages F, Galon J, Dieu-Nosjean MC, Tartour E, Sautes-Fridman C, Fridman WH: Immune infiltration in human tumors: a prognostic factor that should not be ignored. Oncogene 2010, 29:1093-1102

25. Gerlini G, Urso C, Mariotti G, Di Gennaro P, Palli D, Brandani P, Salvadori A, Pimpinelli N, Reali UM, Borgognoni L: Plasmacytoid dendritic cells represent a major dendritic cell subset in sentinel lymph nodes of melanoma patients and accumulate in metastatic nodes. Clin Immunol 2007, 125:184-193

26. Hartmann E, Wollenberg B, Rothenfusser S, Wagner M, Wellisch D, Mack B, Giese T, Gires O, Endres S, Hartmann G: Identification and functional analysis of tumor-infiltrating plasmacytoid dendritic cells in head and neck cancer. Cancer Res 2003, 63:6478-6487

27. Labidi-Galy SI, Treilleux I, Goddard-Leon S, Combes JD, Blay JY, Ray-Coquard I, Caux C, Bendriss-Vermare N: Plasmacytoid dendritic cells infiltrating ovarian cancer are associated with poor prognosis. Oncoimmunology 2012, 1:380-382

28. Sisirak V, Faget J, Gobert M, Goutagny N, Vey N, Treilleux I, Renaudineau S, Poyet G, Labidi-Galy SI, Goddard-Leon S, Durand I, Le Mercier I, Bajard A, Bachelot T, Puisieux A, Puisieux I, Blay JY, Ménétrier-Caux C, Caux C, Bendriss-Vermare N: Impaired IFN- $\alpha$ production by plasmacytoid dendritic cells favors regulatory $\mathrm{T}$-cell expansion that may contribute to breast cancer progression. Cancer Res 2012, 72:5188-5197

29. Faith A, Peek E, McDonald J, Urry Z, Richards DF, Tan C, Santis G, Hawrylowicz C: Plasmacytoid dendritic cells from human lung cancer draining lymph nodes induce Tc1 responses. Am J Respir Cell Mol Biol 2007, 36:360-367

30. Yang L, Carbone DP: Tumor-host immune interactions and dendritic cell dysfunction. Adv Cancer Res 2004, 92:13-27

31. Watkins SK, Zhu Z, Riboldi E, Shafer-Weaver KA, Stagliano KE, Sklavos MM, Ambs S, Yagita H, Hurwitz AA: FOXO3 programs tumor-associated DCs to become tolerogenic in human and murine prostate cancer. J Clin Invest 2011, 121:1361-1372 
32. Brimnes MK, Svane IM, Johnsen HE: Impaired functionality and phenotypic profile of dendritic cells from patients with multiple myeloma. Clin Exp Immunol 2006, 144:76-84

33. Hirohashi Y, Sato N: Tumor-associated dendritic cells: molecular mechanisms to suppress antitumor immunity. Immunotherapy 2011 , 3:945-947

34. Hubert P, Caberg JH, Gilles C, Bousarghin L, Franzen-Detrooz E, Boniver J, Delvenne P: E-cadherin-dependent adhesion of dendritic and Langerhans cells to keratinocytes is defective in cervical human papillomavirus-associated (pre)neoplastic lesions. J Pathol 2005, 206: 346-355

35. Herman L, Hubert P, Herfs $M$, Kustermans G, Henrotin $Y$, Bousarghin L, Boniver J, Delvenne P: The L1 major capsid protein of HPV16 differentially modulates APC trafficking according to the vaccination or natural infection context. Eur J Immunol 2010, 40: 3075-3084

36. Demoulin S, Roncarati P, Delvenne P, Hubert P: Production of large numbers of plasmacytoid dendritic cells with functional activities from CD34(+) hematopoietic progenitor cells: use of interleukin-3. Exp Hematol 2012, 40:268-278

37. Hawiger D, Inaba K, Dorsett Y, Guo M, Mahnke K, Rivera M, Ravetch JV, Steinman RM, Nussenzweig MC: Dendritic cells induce peripheral $\mathrm{T}$ cell unresponsiveness under steady state conditions in vivo. J Exp Med 2001, 194:769-779

38. Delvenne P, Hubert P, Jacobs N: Epithelial metaplasia: an inadequate environment for antitumour immunity? Trends Immunol 2004, 25 : $169-173$

39. Fitzgerald RC, Abdalla S, Onwuegbusi BA, Sirieix P, Saeed IT, Burnham WR, Farthing MJ: Inflammatory gradient in Barrett's oesophagus: implications for disease complications. Gut 2002, 51: 316-322

40. Kornete M, Piccirillo CA: Functional crosstalk between dendritic cells and Foxp3 $(+)$ regulatory $\mathrm{T}$ cells in the maintenance of immune tolerance. Front Immunol 2012, 3:165

41. Matta BM, Castellaneta A, Thomson AW: Tolerogenic plasmacytoid DC. Eur J Immunol 2010, 40:2667-2676

42. Manicassamy S, Pulendran B: Dendritic cell control of tolerogenic responses. Immunol Rev 2011, 241:206-227

43. Janikashvili N, Bonnotte B, Katsanis E, Larmonier N: The dendritic cell-regulatory $\mathrm{T}$ lymphocyte crosstalk contributes to tumor-induced tolerance. Clin Dev Immunol 2011, 2011:430394

44. Albanesi C, Scarponi C, Pallotta S, Daniele R, Bosisio D, Madonna S, Fortugno P, Gonzalvo-Feo S, Franssen JD, Parmentier M, De Pita O, Girolomoni G, Sozzani S: Chemerin expression marks early psoriatic skin lesions and correlates with plasmacytoid dendritic cell recruitment. J Exp Med 2009, 206: 249-258

45. Wijnhoven BP, Tilanus HW, Dinjens WN: Molecular biology of Barrett's adenocarcinoma. Ann Surg 2001, 233:322-337

46. Saraiva M, O'Garra A: The regulation of IL-10 production by immune cells. Nat Rev Immunol 2010, 10:170-181

47. Chieppa M, Bianchi G, Doni A, Del Prete A, Sironi M, Laskarin G, Monti P, Piemonti L, Biondi A, Mantovani A, Introna M, Allavena P: Cross-linking of the mannose receptor on monocyte-derived dendritic cells activates an anti-inflammatory immunosuppressive program. J Immunol 2003, 171:4552-4560

48. Herfs M, Herman L, Hubert P, Minner F, Arafa M, Roncarati P, Henrotin Y, Boniver J, Delvenne P: High expression of PGE2 enzymatic pathways in cervical (pre)neoplastic lesions and functional consequences for antigen-presenting cells. Cancer Immunol Immunother 2009, 58:603-614

49. Troy AJ, Summers KL, Davidson PJ, Atkinson CH, Hart DN: Minimal recruitment and activation of dendritic cells within renal cell carcinoma. Clin Cancer Res 1998, 4:585-593

50. Troy AJ, Davidson PJ, Atkinson CH, Hart DN: CD1a dendritic cells predominate in transitional cell carcinoma of bladder and kidney but are minimally activated. J Urol 1999, 161:1962-1967
51. Gabrilovich DI, Corak J, Ciernik IF, Kavanaugh D, Carbone DP: Decreased antigen presentation by dendritic cells in patients with breast cancer. Clin Cancer Res 1997, 3:483-490

52. Enk AH, Jonuleit H, Saloga J, Knop J: Dendritic cells as mediators of tumor-induced tolerance in metastatic melanoma. Int J Cancer 1997, 73:309-316

53. Chen KJ, Lin SZ, Zhou L, Xie HY, Zhou WH, Taki-Eldin A, Zheng SS: Selective recruitment of regulatory T cell through CCR6CCL20 in hepatocellular carcinoma fosters tumor progression and predicts poor prognosis. PLoS One 2011, 6:e24671

54. De Smedt T, Van Mechelen M, De Becker G, Urbain J, Leo O, Moser M: Effect of interleukin-10 on dendritic cell maturation and function. Eur J Immunol 1997, 27:1229-1235

55. Loser K, Mehling A, Loeser S, Apelt J, Kuhn A, Grabbe S, Schwarz T, Penninger JM, Beissert S: Epidermal RANKL controls regulatory T-cell numbers via activation of dendritic cells. Nat Med 2006, 12:1372-1379

56. Totsuka T, Kanai T, Nemoto Y, Tomita T, Okamoto R, Tsuchiya K, Nakamura T, Sakamoto N, Akiba H, Okumura K, Yagita $\mathrm{H}$, Watanabe M: RANK-RANKL signaling pathway is critically involved in the function of $\mathrm{CD} 4+\mathrm{CD} 25+$ regulatory $\mathrm{T}$ cells in chronic colitis. J Immunol 2009, 182:6079-6087

57. Green EA, Choi Y, Flavell RA: Pancreatic lymph node-derived $\mathrm{CD} 4(+) \mathrm{CD} 25(+)$ Treg cells: highly potent regulators of diabetes that require TRANCE-RANK signals. Immunity 2002, 16:183-191

58. Steinbrink K, Wolfl M, Jonuleit H, Knop J, Enk AH: Induction of tolerance by IL-10-treated dendritic cells. J Immunol 1997, 159: $4772-4780$

59. Leibbrandt A, Penninger JM: TNF conference 2009: beyond bones RANKL/RANK in the immune system. Adv Exp Med Biol 2011, 691:5-22

60. Franz B, Fritzsching B, Riehl A, Oberle N, Klemke CD, Sykora J, Quick S, Stumpf C, Hartmann M, Enk A, Ruzicka T, Krammer PH, Suri-Payer E, Kuhn A: Low number of regulatory $\mathrm{T}$ cells in skin lesions of patients with cutaneous lupus erythematosus. Arthritis Rheum 2007, 56:1910-1920

61. Silva I, Branco JC: Rank/Rank1/opg: literature review. Acta Reumatol Port 2011, 36:209-218

62. Hegde S, Pahne J, Smola-Hess S: Novel immunosuppressive properties of interleukin-6 in dendritic cells: inhibition of NF-kappaB binding activity and CCR7 expression. FASEB J 2004, 18:1439-1441

63. Shurin GV, Shurin MR, Bykovskaia S, Shogan J, Lotze MT, Barksdale EM Jr:: Neuroblastoma-derived gangliosides inhibit dendritic cell generation and function. Cancer Res 2001, 61:363-369

64. Carlos CA, Dong HF, Howard OM, Oppenheim JJ, Hanisch FG, Finn OJ: Human tumor antigen MUC1 is chemotactic for immature dendritic cells and elicits maturation but does not promote Th1 type immunity. J Immunol 2005, 175:1628-1635

65. Kaur BS, Triadafilopoulos G: Acid- and bile-induced PGE(2) release and hyperproliferation in Barrett's esophagus are COX-2 and PKCepsilon dependent. Am J Physiol Gastrointest Liver Physiol 2002, 283:G327-G334

66. Burjonrappa SC, Reddimasu S, Nawaz Z, Gao X, Sharma P, Loggie B: Mucin expression profile in Barrett's, dysplasia, adenocarcinoma sequence in the esophagus. Indian J Cancer 2007, 44:1-5

67. Milano F, Krishnadath KK: Novel therapeutic strategies for treating esophageal adenocarcinoma: the potential of dendritic cell immunotherapy and combinatorial regimens. Hum Immunol 2008, 69: 614-624

68. Monti P, Leone BE, Zerbi A, Balzano G, Cainarca S, Sordi V, Pontillo M, Mercalli A, Di Carlo V, Allavena P, Piemonti L: Tumorderived MUC1 mucins interact with differentiating monocytes and induce IL-10highIL-12low regulatory dendritic cell. J Immunol 2004, 172:7341-7349

69. Loos M, Langer R, Schuster T, Gertler R, Walch A, Rauser S, Friess H, Feith M: Clinical significance of the costimulatory molecule B7-H1 in Barrett carcinoma. Ann Thorac Surg 2011, 91:1025-1031 